\title{
Air quality and health effects of biogenic volatile organic compounds emissions from urban green spaces and the mitigation strategies ${ }^{2 /}$
}

\author{
Yuan Ren ${ }^{\mathrm{a}}$, Zelong Qu ${ }^{\mathrm{a}}$, Yuanyuan Du ${ }^{\mathrm{a}}$, Ronghua Xu ${ }^{\mathrm{a}}$, Danping Ma ${ }^{\mathrm{b}}$, Guofu Yang ${ }^{\mathrm{a}}$, \\ Yan Shi ${ }^{c}$, Xing Fan ${ }^{a}$, Akira Tani ${ }^{\mathrm{d}}$, Peipei Guo ${ }^{\mathrm{e}}$, Ying Ge ${ }^{\mathrm{a}}$, Jie Chang ${ }^{\mathrm{a},{ }^{*}}$ \\ a College of Life Sciences, Zhejiang University, Hangzhou 310058, PR China \\ ${ }^{\mathrm{b}}$ Engineering Experimental Training Center, Zhejiang University of Water Resources and Electric Power, Hangzhou 310018, PR China \\ c School of Landscape Architecture, Zhejiang A \& F University, Lin'an 311300, PR China \\ ${ }^{\mathrm{d}}$ Institute for Environmental Sciences, University of Shizuoka, 52-1 Yada, Shizuoka 422-7 8526, Japan \\ ${ }^{\mathrm{e}}$ Research Center for Eco-Environmental Sciences, Chinese Academy of Sciences, Beijing 100085, PR China
}

\section{A R T I C L E I N F O}

\section{Article history:}

Received 7 March 2017

Received in revised form 14 June 2017

Accepted 14 June 2017

Available online 20 July 2017

\section{Keywords:}

Urban area

$\mathrm{PM}_{2.5}$

Ozone pollution

Isoprene

Monoterpenes

\begin{abstract}
A B S T R A C T
Biogenic volatile organic compounds (BVOCs) emissions lead to fine particulate matter $\left(\mathrm{PM}_{2.5}\right)$ and ground-level ozone pollution, and are harmful to human health, especially in urban areas. However, most BVOCs estimations ignored the emissions from urban green spaces, causing inaccuracies in the understanding of regional BVOCs emissions and their environmental and health effects. In this study, we used the latest local vegetation datasets from our field survey and applied an estimation model to analyze the spatial-temporal patterns, air quality impacts, health damage and mitigating strategies of BVOCs emissions in the Greater Beijing Area. Results showed that: (1) the urban core was the hotspot of regional BVOCs emissions for the highest region-based emission intensity $\left(3.0 \mathrm{~g} \mathrm{C} \mathrm{m}^{-2} \mathrm{yr}^{-1}\right)$ among the 11 subregions; (2) urban green spaces played much more important roles (account for $62 \%$ of total health damage) than rural forests in threating human health; (3) BVOCs emissions from green spaces will more than triple by 2050 due to urban area expansion, tree growth and environmental changes; and (4) adopting proactive management (e.g. adjusting tree species composition) can reduce $61 \%$ of the BVOCs emissions and $50 \%$ of the health damage related to BVOCs emissions by 2050 .
\end{abstract}

() 2017 Elsevier Ltd. All rights reserved.

\section{Introduction}

Volatile organic compounds (VOCs), including both biogenic sources (BVOCs) and anthropogenic sources (AVOCs), contribute to the formation of ground-level ozone and secondary organic aerosols (SOA), with great impacts on outdoor air pollution (Laothawornkitkul et al., 2009; Simpson and McPherson, 2011; Mochizuki et al., 2015). In particular, BVOCs originating from vegetation are believed to play more important roles owing to their higher source strengths and chemical reactivity compared with AVOCs (Guenther et al., 1995; Atkinson, 2000; Harrison et al., 2013). BVOCs induced increments in the atmospheric ozone and fine particulate matter $\left(\mathrm{PM}_{2.5}\right)$ concentrations will further increase

\footnotetext{
* This paper has been recommended for acceptance by Klaus Kummerer.

* Corresponding author. Department of Biological Science, College of Life Sciences, Zhejiang University, 866 Yuhangtang Road, Hangzhou 310058, PR China.

E-mail address: jchang@zju.edu.cn (J. Chang).
}

human's respiratory and cardiovascular mortality risks (Heal et al., 2013; Lelieveld et al., 2015; Madaniyazi et al., 2016). Nevertheless, only a few quantitative studies have been carried out to investigate the environmental and health outcomes of BVOCs (Benjamin and Winer, 1998; Ghirardo et al., 2016).

Urban areas are hotspots of air pollution and health damages. At present, more than half of the world's population lives in urban areas, and this ratio is expected to reach $70 \%$ by 2050 (Ramalho and Hobbs, 2012). Following the continuous urban expansion worldwide and the urban population's growing demands for ecosystem services, urban green spaces have expanded even faster than the increase in urban population (Fuller and Gaston, 2009; Seto et al., 2012). However, in addition to providing various regulating services and cultural services (Escobedo et al., 2011; Pataki et al., 2011), green spaces also become an important contributor to regional BVOCs emissions (Chang et al., 2012; Calfapietra et al., 2013). As the atmosphere in urban area is often dominated by VOC-limited regimes due to high anthropogenic NOx emissions, green spaces may contribute significantly to ozone production (Carter, 2007; 
Calfapietra et al., 2013). Moreover, when BVOCs from green spaces occur in urban areas with high human population densities, they can have much greater health damages than those from natural forests (Ren et al., 2014). The neglect of urban BVOCs emissions may result in significant underestimations of regional and global emissions. More importantly, the health losses associated with BVOCs emissions in urban areas will be greatly underestimated.

Numerous efforts have been made worldwide to quantify BVOCs emissions across different spatial and temporal scales (Klinger et al., 2002; Steinbrecher et al., 2009; Guenther et al., 2012; Oderbolz et al., 2013). Nevertheless, only a few case studies focused on estimating BVOCs emissions from urban areas (Chang et al., 2012; Dunn-Johnston et al., 2016) due to the lack of suitable methods for studying urban vegetation (Kaye et al., 2006; Guenther et al., 2012). As the result of a warmer climate, together with improvements in gardening practices, urban greenings have brought together a rich mixture of species to improve the biodiversity and aesthetic values of cities, forming species compositions that are distinct from surrounding rural forests (Niinemets and Peñuelas, 2008). Since BVOCs emissions are species specific (Benjamin et al., 1996; Tani and Kawawata, 2008), the different species compositions between urban and rural areas may lead to significant disparities in BVOCs emission patterns (Chang et al., 2012). The urban heat island effect and different light conditions through the canopy can further enlarge the regional disparity (Ren et al., 2014). BVOCs estimations that fully consider the human management factors and the specific environmental factors in urban areas are thus urgently required.

In this study, we chose a megacity, the Greater Beijing Area, as a case study. As the capital city of China, Beijing is one of the largest and most developed cities in China. In recent years, ozone pollution in Beijing has been aggravated despite a significant decline in anthropogenic emissions by the implementation of various control measures (Wang et al., 2015a; Li et al., 2016a). The contrasting trends may be explained by the rapid increase of BVOCs emissions. The aim of this study is to (1) investigate the BVOCs emissions from urban green spaces; (2) quantify the air quality impacts and health damage associated with BVOCs emissions; and (3) discuss the effectiveness of green space management strategies on mitigating future BVOCs emissions to aid decision making.

\section{Materials and methods}

\subsection{Study area}

The Greater Beijing Area $\left(39^{\circ} 28^{\prime}-41^{\circ} 25^{\prime} \mathrm{N}, 115^{\circ} 25^{\prime}-117^{\circ} 130^{\prime} \mathrm{E}\right)$ is located in the northeast of the North China plain, containing an urban core and periphery, covering a total land area of $16,410 \mathrm{~km}^{2}$. This region is characterized by a temperate, humid, continental monsoon climate, with annual average temperature $11-12{ }^{\circ} \mathrm{C}$ and annual precipitation around $500 \mathrm{~mm}$. Beijing has been undergoing rapid urbanization and its built-up area increased from $397 \mathrm{~km}^{2}$ in 1990 to $1386 \mathrm{~km}^{2}$ in 2015 (NBSC, 1991-2015). The city has also been plagued by serious air pollution for years (Cumming et al., 2014). In 2015, its annual average $\mathrm{PM}_{2.5}$ concentration and $\mathrm{O}_{3-8 \mathrm{~h}}$ 90 per concentration (90th percentile of the daily maximum 8-h average ozone concentrations) were $80.6 \mu \mathrm{g} \mathrm{m}^{-3}$ and $202.6 \mu \mathrm{g} \mathrm{m}^{-3}$, which exceeded the National Ambient Air Quality Standards (GB 3095-2012) Grade II by 1.3 and 0.3 times, respectively (BMEPB , 2016).

\subsection{Field measurement and data collection}

In this study, we divided the Greater Beijing Area into 11 subregions: an urban core, 5 semi-urbanized sub-regions, and 5 less urbanized rural sub-regions (Fig. 1A). We conducted an urban vegetation survey in the years 2012, 2013 and 2016. Urban green spaces were divided into five types: street green space, park green space, affiliated green space (in schools and institutional units), protection green space (e.g. greenbelts, windbreak green space) and residential green space. A stratified random selection method was applied and a total of 282 plots $\left(400 \mathrm{~m}^{2}\right)$ were investigated. In each plot, tree attributes for species (Table S1), stem diameter at breast height $(\mathrm{DBH})$, and tree height of all trees $(\mathrm{DBH}>2.5 \mathrm{~cm})$ were recorded. Historical data on the number of trees, species composition and areal extent of green spaces were collected from published literature (BGGB, 1995-2005; Ghirardo et al., 2016).

Natural forests were divided into 22 forest types based on their dominant tree species (Table S2). The data of forest area, tree density, spatial distribution, and DBH of each forest type were from the latest (8th) national forest resource inventory (2009-2013) and published literature (Li et al., 2011; Luo et al., 2013). Historical forest areas by age classes as well as by forest types were derived from the 2nd-7th national forest resource inventory (SFAC, 1982-2010). Specific leaf area (SLA) and annual increment of DBH (Tables S3 and S4) of different tree species were also collected to simulate the changes in leaf area index (LAI) and foliar mass during tree growth.

BVOCs were grouped into four categories: isoprene, monoterpenes, sesquiterpenes, and other VOCs (OVOCs). The raw emission rates (Table S5-S7) measured in our previous studies (Chang et al., 2012; Ren et al., 2014) and other studies (e.g. Klinger et al., 2002; Wang et al., 2003) were assigned to primary tree species using a taxonomic approach (Benjamin et al., 1996). All these emission rates have been standardized as basal emission rates under standard environmental conditions. The light dependent fraction (LDF) of moneterpenes was obtained from published literature (Table S8). In this study, we defined a tree species as highemitting species if the sum of its isoprene and monoterpenes basal emission rates exceeded $10 \mu \mathrm{g}$ of $\mathrm{C} \mathrm{g}^{-1} \mathrm{~h}^{-1}$; if the sum is less than $10 \mu \mathrm{g}$ of $\mathrm{Cg}^{-1} \mathrm{~h}^{-1}$ and higher than $1 \mu \mathrm{g}$ of $\mathrm{Cg}^{-1} \mathrm{~h}^{-1}$, the species was defined as middle-emitting species; otherwise it is a low-emitting species (Ren et al., 2014).

To calculate the environmental corrections on BVOCs emissions, hourly air temperature and photosynthetically active radiation (PAR) data obtained from the meteorological data center of the China Meteorological Administration and monthly $\mathrm{CO}_{2}$ concentration data from the Shangdianzi Baseline Observatory were used.

Base incremental reactivity (Carter, 2007) and fractional aerosol coefficient (e.g. Griffin et al., 1999; Karl et al., 2009; Kiendler-Scharr et al., 2012) of different BVOCs species were collected (Table S9) to estimate the effects of BVOCs on air quality. Besides BVOCs, other precursors exist for both ozone and SOA. To assess the relative contributions of BVOCs and other precursors, we also collected the summertime ambient concentrations of AVOCs, carbon monoxide and methane, and the chemical speciation of AVOCs from published literature (Wang et al., 2015b; Li et al., 2015b; Li et al., 2016a; CNEMC, 2016).

\subsection{Calculation of BVOCs emissions}

In this study, the basic BVOCs algorithms are derived from the widely used equations by Guenther (Guenther et al., 1995; Guenther et al., 1999) and are revised based on other studies (Staudt et al., 2000; Heald et al., 2009). Isoprene emission was treated as synthesis emission (light-dependent); sesquiterpenes and OVOCs were treated as pool emissions (light-independent); while monoterpenes were assumed to have both synthesis emissions and pool emissions (Steinbrecher et al., 2009; Oderbolz et al., 2013). The synthesis isoprene $\left(E_{I S P}\right)$ and monoterpenes ( $\left.E_{M N S}\right)$ emissions were quantified as: 

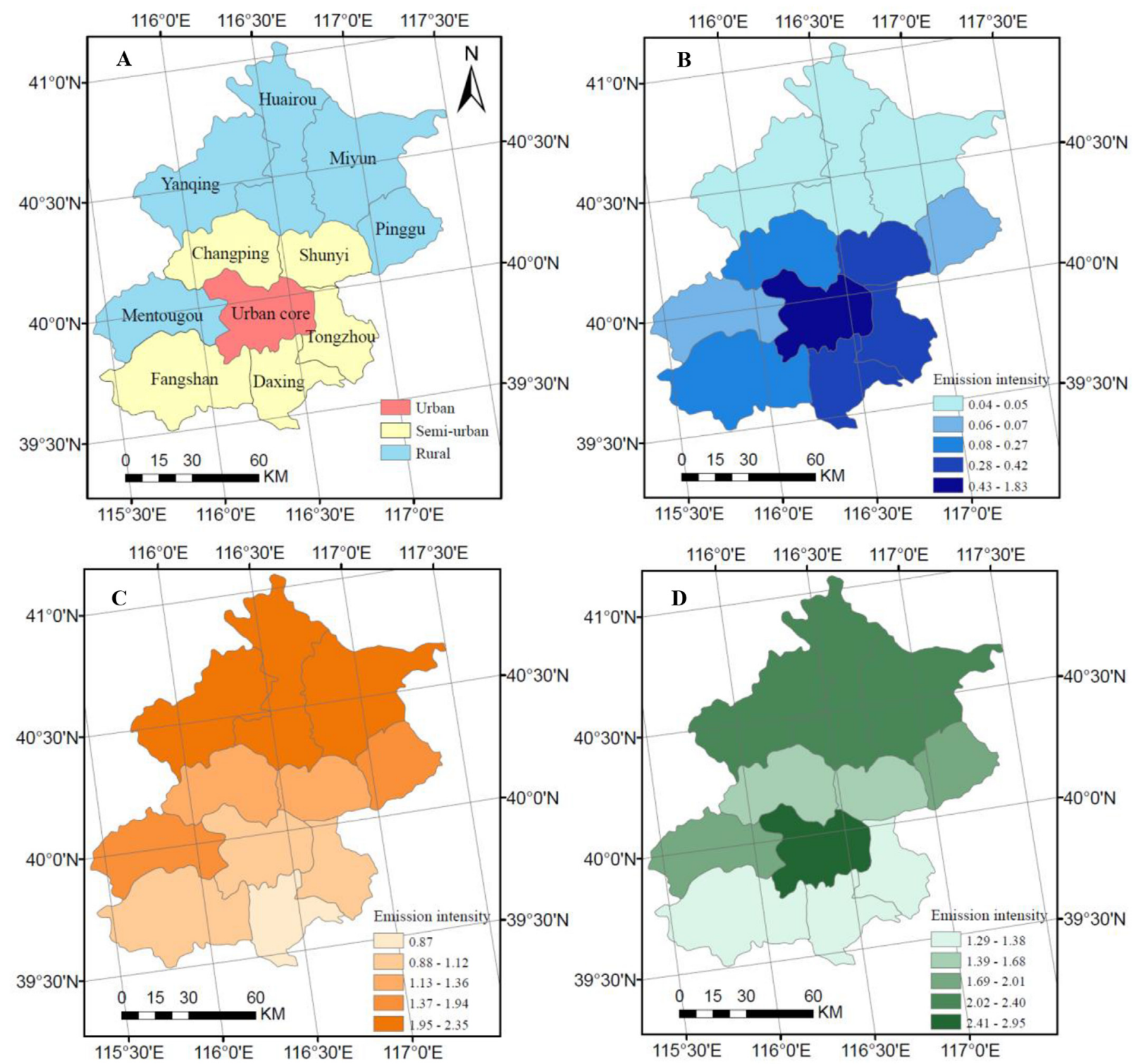

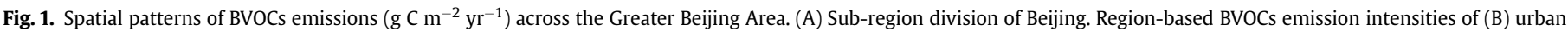
green spaces, (C) natural forests, and (D) total vegetation (green spaces + natural forests).

$E_{I S P}=\varepsilon_{I S P} D \gamma_{T} \gamma_{P} \gamma_{S} \gamma_{C}$

$E_{M N S}=\varepsilon_{M N S} D \gamma_{T} \gamma_{P} \gamma_{S}$

where $\varepsilon$ is the basal emission rate ( $\mu \mathrm{g} \mathrm{C} \mathrm{g}^{-1} \mathrm{~h}^{-1}$ ) at standard conditions (i.e. $30^{\circ} \mathrm{C}$ leaf temperature and $1000 \mu \mathrm{mol} \mathrm{m}^{-2} \mathrm{~s}^{-1}$ PAR); $D$ is the peak foliar mass $(\mathrm{g}) ; \gamma_{T}, \gamma_{P}$, and $\gamma_{S}$ are environmental correction factors accounting for the influence of temperature, light intensity, and seasonal variation on synthesis emissions; and $\gamma_{C}$ is the $\mathrm{CO}_{2}$ inhibition on isoprene emission. We used allometric equations related to DBH or related to both DBH and tree height to calculate the peak leaf biomass $(D)$ of each tree species (or forest types) in each sub-region (Table S10). As the leaf-to-air temperature difference was quite small in urban areas (Meier and Scherer,
2012), we used air temperature instead of leaf temperature to calculate the temperature correction factor $\left(\gamma_{T}\right)$. PAR and LAI were used to calculate the light correction factor $\left(\gamma_{P}\right)$; atmospheric $\mathrm{CO}_{2}$ concentrations were used to calculate the $\mathrm{CO}_{2}$ correction factor $\left(\gamma_{C}\right)$. As light varies dramatically within a tree canopy resulting in much lower emissions, a simple canopy model was applied to simulate the light conditions at different canopy layers (Geron et al., 1994).

The pool monoterpenes $\left(E_{M N P}\right)$, sesquiterpenes $\left(E_{S Q T}\right)$, and OVOCs ( $\left.E_{\text {OVP }}\right)$ emissions were quantified as:

$E_{M N P}=\varepsilon_{M N P} D \gamma_{T} \gamma_{S}$ 
$E_{S Q T}=\varepsilon_{S Q T} D \gamma_{T} \gamma_{S}$

$E_{O V P}=\varepsilon_{O V P} D \gamma_{T} \gamma_{S}$

where $D, \gamma_{T}$, and $\gamma_{P}$ has the same meaning as those in equation (1). The details and calculations of $D, \gamma_{T}, \gamma_{B} \gamma_{C}, \gamma_{S}$ and the canopy model are found in the Appendix. Besides the impact factors mentioned above, BVOCs emissions may also be influenced by many abiotic (e.g. ozone, pruning) and biotic (e.g. herbivory) stresses in urban environment (Peñuelas and Staudt, 2010; Mentel et al., 2013; Ghirardo et al., 2016). Analyzing plant responses and adaptations to these urban conditions, defined as 'urban plant physiology' by Calfapietra et al. (2015), could achieve more accurate BVOCs estimations. However, these "stress-induced" emissions have not been well studied (Oderbolz et al., 2013) so our study is mainly limited to stress-free conditions.

In each sub-region $i$, the total emissions of each BVOCs category $j$ $\left(E_{i, j}\right)$ can be calculated as the sum of emissions from green spaces $\left(E G_{i, j}\right)$ and natural forests $\left(E F_{i, j}\right)$ :

$E_{i, j}=E G_{i, j}+E F_{i, j}$

In this study, two kinds of emission intensity were distinguished to quantify the source strengths of BVOCs emissions: one was the region-based emission intensity (defined as BVOCs emissions per unit administrative land area); the other was vegetation-based emission intensity (BVOCs emissions per unit land area occupied by vegetation). The former was used to characterize the emissions of a specific region, while the latter only focused on emission intensity of vegetated area.

We built a dynamic model to further investigate the temporal trends of BVOCs emissions and the role of management strategies in mitigating those emissions. The model was an updated version of our previous model (Ren et al., 2014), which was developed based on the STELLA graphic programming system (High Performance Systems, Inc., Version 9.1.2). In the new version, we added the canopy model and the calculation of light dependent monoterpenes emissions and sesquiterpenes emissions. The model included two parts. Part 1 was used to simulate processes like green space expansion, the tree planting/replacement, afforestation and tree growth with a temporal resolution of one year (Fig. S1). The input of part 1 included the areal extent, species composition, tree density and age distribution of each vegetation type, and the peak leaf biomass of individual tree in each age group for each tree species. The output of part 1 was the peak leaf biomass of each tree species in each simulation year. Part 2 used species-specific basal emission rates, hourly meteorological data (temperature, $\mathrm{PAR}$ ), $\mathrm{CO}_{2}$ concentration data and the output of part 1 as its inputs and used the algorithms outlined above to simulate the hourly BVOCs emissions for each tree species in each sub-region (Fig. S2). The time step and temporal resolution of part 2 was $1 \mathrm{~h}$. The details of the estimation model are discussed in the Appendix.

\subsection{Air quality impacts and health damage estimation}

We applied the "fractional aerosol coefficient" method to roughly estimate the effects of BVOCs emissions on aerosol formation. The fractional aerosol coefficient is defined as the fraction of aerosol that would result from reactions with a particular VOC (Mentel et al., 2013). We used the "incremental reactivity" method to estimate the effects of BVOCs emissions on ozone pollution. Incremental reactivity was defined as the amount of ozone formed when per unit of VOC was added to a representative air mixture (Carter, 1994; Zheng et al., 2009). Based on the above two methods, we used a simple box model to calculate the air quality impacts of BVOCs emissions. In each sub-region $i$, the concentration increments of secondary organic aerosols $\left(C_{S O A}\right)$ and ozone $\left(C_{o z o n e}\right)$ related to the emission of a specific BVOC category $j$ were calculated as:

$$
\begin{gathered}
C_{S O A(i, j)}=\frac{E_{i, j} \times F A C_{j}}{S_{i} \times h} \times \tau_{S O A} \\
C_{\text {Ozone }(i, j)}=\frac{E_{i, j} \times \tau_{B V O C_{j}}}{S_{i} \times h} \times I R_{j}
\end{gathered}
$$

where $E_{i, j}$ is the BVOCs emissions estimated from this study; $S$ is the administrative land area of each sub-region $\left(\mathrm{km}^{2}\right)$ (Table S11); $h$ $(2 \mathrm{~km})$ is the typical proxy for the height of an inversion layer (Ghirardo et al., 2016); $\tau$ is the atmospheric lifetime of SOA or BVOCs (Table S12). IR and FAC are the base incremental reactivity and fractional aerosol yield of BVOCs. To assess the actual role of BOVCs in urban ozone pollution, we compared the relative significance of all important sources. The ozone formation potentials of AVOCs, carbon monoxide, and methane were calculated by multiplying their ambient concentrations collected from published literature by the chemical species-specific incremental reactivity (Carter, 2007).

We then combined the concentration increment results and population density data to evaluate the health damage attributable to ozone and $\mathrm{PM}_{2.5}$ pollution in each sub-region $i$ :

$H D_{i}=C_{i} \times \operatorname{Pop}_{i}$

where $C_{i}$ is the concentration increment of pollutant (ozone or $\mathrm{PM}_{2.5}$ ) caused by BVOCs emissions; $\mathrm{Pop}_{i}$ is the population of each sub-region (Table S11).

\subsection{Sensitivity analysis and scenarios preparation}

To explore the mechanisms for the differences between BVOCs emissions from urban green spaces and natural forests, we performed a series of sensitivity calculations for the year 2015. We first calculated the 'basal' emission intensity (vegetation-based) of urban green spaces assuming they had the same species composition and exposure to the same environmental conditions as rural forests. After that, three main factors that affect BVOCs emissions, including urban heat island effect, different vegetation compositions, and light conditions, have been added one by one to compute their contributions to enhanced urban BVOCs emissions.

We then developed a baseline scenario and several urban management scenarios to help understand the role of urban management strategies in determining future urban BVOCs emissions and their associated health outcomes. We took 2015 as the reference year and 2050 as the target year. In the baseline scenario, the mean annual temperature of Beijing in 2050 is projected to be $1.9^{\circ} \mathrm{C}$ higher than present under the Representative Concentration Pathways (RCP) 4.5 simulations (Chen and Frauenfeld, 2016); the variations of $\mathrm{CO}_{2}$ concentration ( $+3.5 \mathrm{ppm} \mathrm{yr}^{-1}$ ) (Fang et al., 2014), urban heat island intensity $\left(+0.029^{\circ} \mathrm{C} \mathrm{yr}^{-1}\right)$ and urban green space

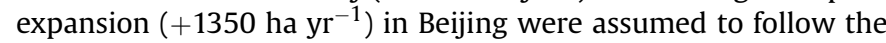
current trends (Zhao et al., 2011; NBSC, 2010-2016); considering the land limits in Beijing, natural forests were assumed to expand at a low rate and achieve a $10 \%$ increase by 2050 ; tree growth was considered while other factors that influence BVOCs emissions (e.g. tree density, species composition and PAR) were assumed to be constant over time since 2015.

Management scenarios include practices that could directly change vegetation characteristics and environmental conditions. In 
the species composition scenario (S1), the species composition of newly planted trees was optimized based on their BVOCs emission potentials, that is, change $50 \%$ of the high-emitting species to combinations of low-emitting species. Under the tree density scenario (S2), the current way of increasing vegetation quantity through increasing the green space ratio will be replaced by an increase in tree density in the existing green spaces. In the tree replacement scenario $(\mathrm{S} 3)$, the species composition of existing trees will be optimized, i.e., 50\% of high-emitting species will be replaced by low-emitting species. In the urban heat island mitigation scenario (S4), measures will be implemented to keep the current urban heat island intensity unchanged. Finally, a synthetic scenario that combined all management strategies (S5, "synthetic") was constructed.

\subsection{Uncertainty calculation}

We conducted a Monte Carlo simulation (10,000 runs) to characterize the uncertainties associated with our estimates of BVOCs emissions and their effects. More than 20 model parameters and input variables have been assumed to vary and have been randomly sampled (Table S13). The medians and 95\% confidence intervals were calculated and used to represent the uncertainties associated with our estimates.

\section{Results and discussion}

\subsection{Urban core is the hotspot of BVOCs emissions in Beijing}

Marked differences in BVOCs emissions across Beijing can be observed, mainly due to the different species composition and vegetation coverage among various sub-regions (Fig. 1A). For BVOCs emissions from urban green spaces, the urban core had the biggest green space ratio (28\%) and thus also had the highest region-based emission intensity $\left(1.8 \mathrm{~g} \mathrm{C} \mathrm{m}^{-2} \mathrm{yr}^{-1}\right)$. The five newly developed sub-regions, Daxing, Shunyi, Tongzhou, Fangshan and Changping, had moderate region-based emission intensities (0.2-0.4 $\left.\mathrm{g} \mathrm{C} \mathrm{m}^{-2} \mathrm{yr}^{-1}\right)$ for they were experiencing rapid urbanization and green space expansion. The remaining five rural subregions were less urbanized and had the lowest emission intensities (Fig. 1B). For BVOCs emissions from natural forests, the highest emissions occurred in the three northern rural sub-regions of Miyun, Huairou, and Yanqing (mean $=2.3 \mathrm{~g} \mathrm{C} \mathrm{m}^{-2} \mathrm{yr}^{-1}$ ), while the three southern semi-urban sub-regions had the lowest emission intensities (Fig. 1C).

When BVOCs emissions from green spaces and natural forests were combined, the urban core exhibited the highest region-based emission intensity ( $3.0 \mathrm{~g} \mathrm{C} \mathrm{m}^{-2} \mathrm{yr}^{-1}$ ), followed by the 5 rural subregions (Mean $=2.2 \mathrm{~g} \mathrm{C} \mathrm{m}^{-2} \mathrm{yr}^{-1}$ ). The 5 semi-urban sub-regions had even lower emission intensities (Mean $=1.4 \mathrm{~g} \mathrm{C} \mathrm{m}^{-2} \mathrm{yr}^{-1}$ ) (Fig. 1D). In the past, urbanization is often treated as a process that would reduce regional BVOCs emissions (Tai et al., 2013; Unger, 2014). Our study provided empirical evidence that urban expansion does not necessarily reduce regional BVOCs emissions. In contrast, urban areas could be hotspots of regional BVOCs emissions (Fig. 1D).

\subsection{Green spaces have higher vegetation-based BVOCs emission intensity than natural forests}

The urban core had the highest emissions can be explained by the fact that the average vegetation-based BVOCs emission intensity of green spaces ( $7.3 \mathrm{~g} \mathrm{C} \mathrm{m}^{-2} \mathrm{yr}^{-1}$ ) was higher than that of natural forests $\left(6.5 \mathrm{~g} \mathrm{C} \mathrm{m}^{-2} \mathrm{yr}^{-1}\right)$ in Beijing (Fig. 2). Among the five types of green spaces, the protection green space had the highest

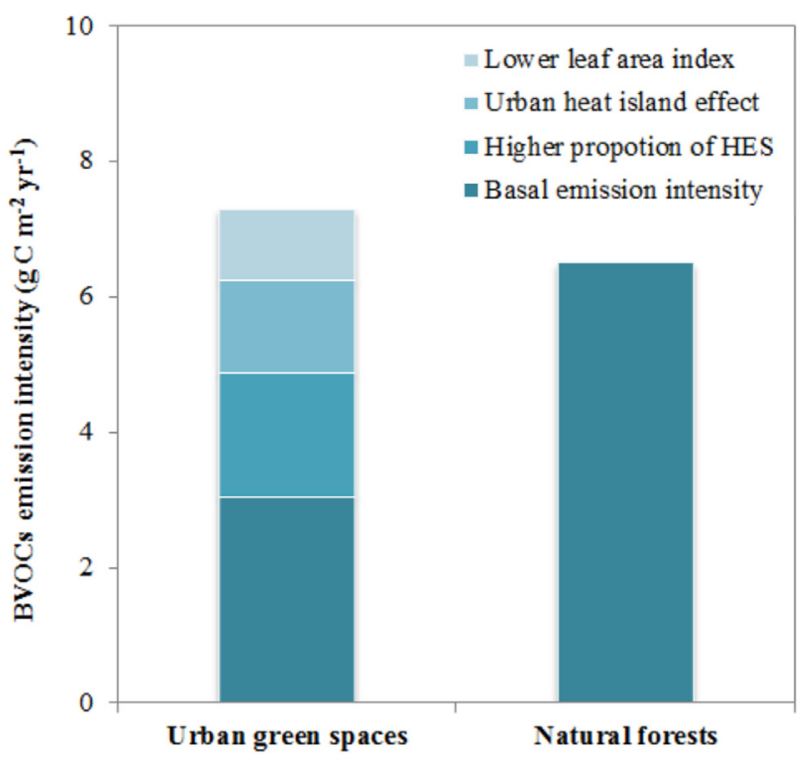

Fig. 2. Comparison of vegetation-based BVOCs emission intensity between urban green spaces and natural forests. HES: high-emitting species. Urban green spaces had better light conditions for BVOCs emissions due to their lower LAI than natural forests.

emission intensity (11.6 $\mathrm{g} \mathrm{C} \mathrm{m}^{-2} \mathrm{yr}^{-1}$ ), followed by the street green space $\left(7.0 \mathrm{~g} \mathrm{C} \mathrm{m}^{-2} \mathrm{yr}^{-1}\right)$ and residential green space $\left(6.7 \mathrm{~g} \mathrm{C} \mathrm{m}^{-2}\right.$ $\left.\mathrm{yr}^{-1}\right)$. Only the park green space and affiliated green space had lower emission intensity than natural forests.

Based on the sensitivity analysis, urbanized green spaces have lower tree densities and smaller tree sizes compared to its surrounding natural forests, thus the average 'basal' emission intensity of green spaces should be $53 \%$ lower than natural forests (Fig. 2). However, there are many positive factors that could facilitate urban BVOCs emissions (Niinemets and Peñuelas, 2008; Chang et al., 2012). In urban landscapes of Beijing, some tree species with high emission potentials, such as species in Populus, Sophora, and Salix, are very popular and widely used (Table S1). As a result, urban green spaces have larger proportions of high-emitting species or genus than its surrounding natural forests, which could greatly enhance $(+60 \%)$ the emissions of urban green spaces. The urban heat island effect $\left(1.8^{\circ} \mathrm{C}\right)$ further increases urban BVOCs emissions by $28 \%$. In addition, as urban green space has lower tree densities and LAI thus has better light conditions within the canopy (Guenther et al., 1995), this could enhance those light dependent emissions and achieve another $17 \%$ increase in urban emissions (Fig. 2).

Influenced by all these factors, the vegetation-based emission intensity of urban green spaces was $12 \%$ higher than that of natural forests in Beijing (Fig. 2). Similar result can also be found in previous studies conducted in Hangzhou and Ningbo (Chang et al., 2012; Guo et al., 2013). However, the green spaces of Beijing had higher vegetation-based emission intensities than those of green spaces in other cities (Papiez et al., 2009; Chang et al., 2012; Guo et al., 2013), implying that Beijing was facing a more challenging situation to control its urban BVOCs emissions.

\subsection{BVOCs contribute significantly to urban ozone pollution in summer}

In 2015, BVOCs emissions led to an average of $5.7 \mu \mathrm{g} \mathrm{m}^{-3}$ increment in the annual atmospheric ozone concentrations. The urban core had the highest ozone formation potential, followed by the 5 rural sub-regions (Fig. $3 \mathrm{~A}$ ). As BVOCs emissions undergo 

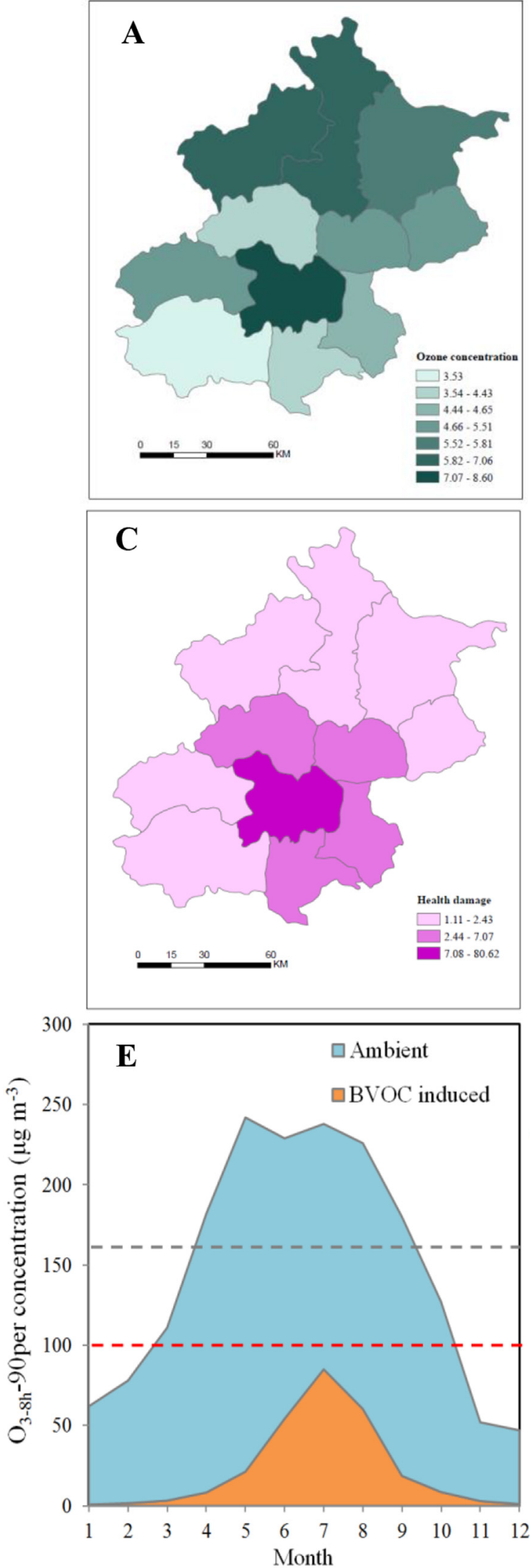
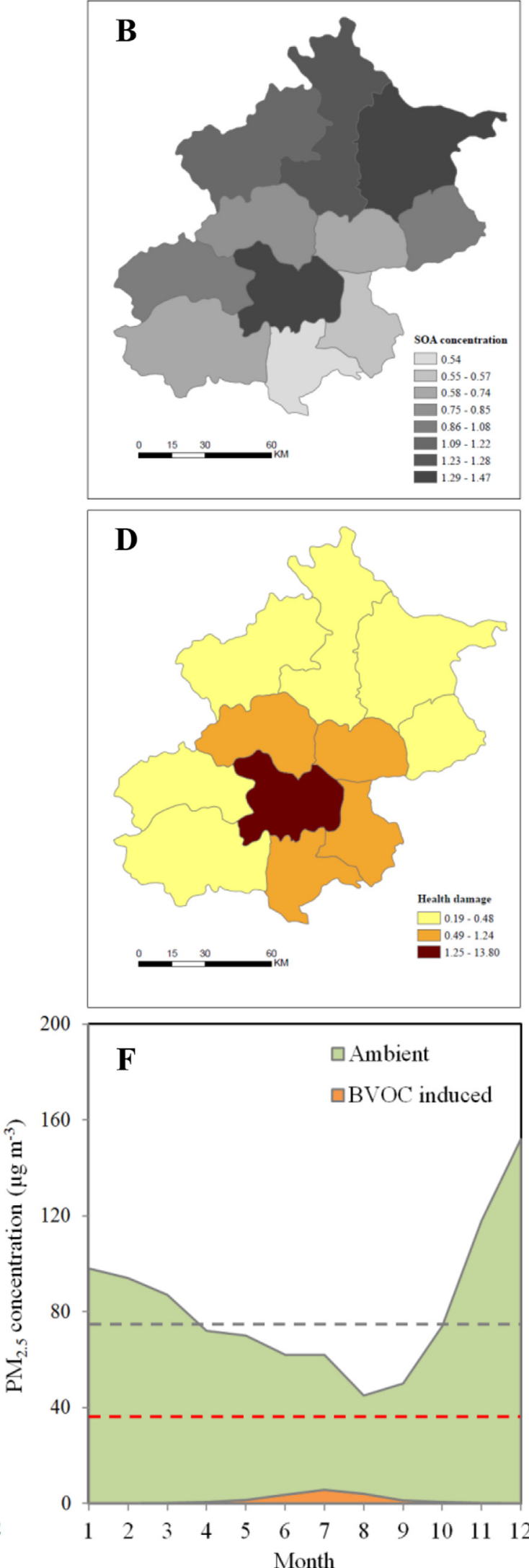

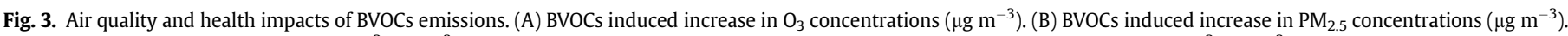

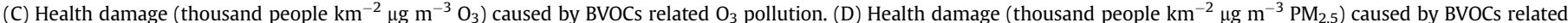

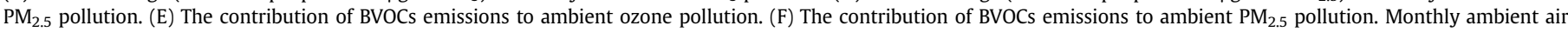

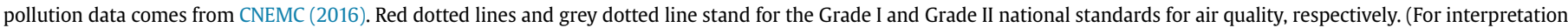
of the references to colour in this figure legend, the reader is referred to the web version of this article.) 
strong seasonal and diurnal variations (Staudt et al., 2000; Guenther et al., 2012), the induced ozone concentration increment could be significant in the daytime during summer. In July, BVOCs emissions were responsible for an $71.5 \mu \mathrm{g} \mathrm{m}^{-3}$ increment in $\mathrm{O}_{3-8 \mathrm{~h}} 90$ per concentration in the urban core, accounting for about $30 \%$ of the ambient concentration and $70 \%$ of the Grade I national air quality standard (GB 3095-2012) for ozone (Fig. 3E). The relatively high contribution of BVOCs to ozone formation in summer can also be found in other studies. For example, BVOCs emissions substantially led to a $22 \mu \mathrm{g} \mathrm{m}^{-3}$ increase in urban ozone concentration in Osaka Prefecture, accounting for $15.9 \%$ of the mean daily maximum 1-h $\mathrm{O}_{3}$ concentration (Nishimura et al., 2015). In the Yangtze River Delta, BVOCs emissions contributed between 18.6 and $24.9 \%$ to daytime $\mathrm{O}_{3-8 \mathrm{~h}}$ concentration ( $\mathrm{Li}$ et al., 2016b). In Beijing, although BVOCs emissions were lower than anthropogenic emissions, their contribution to urban ozone pollution could be significant owing to their higher ozone formation potentials (IR) compared with anthropogenic pollutants.

To compare the relative significance of BVOCs and other ozone precursors, we also calculated the ozone formation potentials of AVOCs, $\mathrm{CO}$, and $\mathrm{CH}_{4}$ using the incremental reactivity method. NOx was not included since the urban core of Beijing was under "VOClimited" regimes, and ozone formation was not sensitive to NOx concentrations (Zhang et al., 2014; Li et al., 2015b). Results showed that, BVOCs, AVOCs, $\mathrm{CO}$ and $\mathrm{CH}_{4}$ contributed $22 \%, 43 \%, 27 \%$ and $8 \%$, respectively, to ozone formation in the urban core in summertime. In Beijing, mitigation of anthropogenic pollutants had been listed as the priority to mitigate ozone pollution (Wang et al., 2015a). However, if the high ozone background caused by BVOCs emissions is not taken into account (Fig. 3F), the effectiveness of the current measures for controlling ozone will be compromised.

In 2015, BVOCs emissions led to an average of $1.1 \mu \mathrm{g} \mathrm{m}^{-3}$ increments in the annual atmospheric $\mathrm{PM}_{2.5}$ in Beijing, accounting for $1.3 \%$ of the monitored ambient $\mathrm{PM}_{2.5}$ concentrations (CNEMC, 2016). The strongest aerosols formation occurred in the urban core and Miyun sub-region in the northeast, mainly due to their high monoterpenes emissions (Fig. 3B). In the urban core, the estimated $\mathrm{PM}_{2.5}$ formation via BVOCs $\left(1.5 \mu \mathrm{g} \mathrm{m}^{-3}\right)$ in this study was about 26\% lower than a previous estimation (Ghirardo et al., 2016). This disparity between the two studies may result from the different BVOCs inventories used. In our study, we only calculated constitutive biogenic emissions, while Ghirardo et al. (2016) also considered stress-induced emissions. To evaluate the relative contribution of stress-induced emissions, we conducted a sensitive analysis by using the latest species-specific induced emission rates (for monoterpenes and sesquiterpenes) from Ghirardo et al. (2016) to rerun the model. Results showed that our new estimate of $\mathrm{PM}_{2.5}$ formation via BVOCs emissions in 2010 was only 2.5\% lower than Ghirardo et al. (2016) after considering stress-induced emissions.

In previous studies, the aerosols formation potentials of AVOCs in Beijing have been estimated using the same fractional aerosol coefficient method as this study (Ghirardo et al., 2016; Sun et al., 2016). The aerosol formation potential of AVOCs (7.9-44.3 $\mu \mathrm{g} \mathrm{m}^{-3}$ ) in these studies was much higher than what we estimated for BVOCs, indicating that AVOCs were by far the dominant precursors of SOA formation in Beijing. Besides SOA, particulate pollution in Beijing also has many other primary and secondary sources. As a result, BVOCs load in the urban air made limited contribution to ambient $\mathrm{PM}_{2.5}$ pollution in all seasons, even account for the uncertainties of our estimates (Fig. 3F).

\subsection{Urban green spaces play more important roles than natural forests in damaging human health}

In 2015, the ozone and $\mathrm{PM}_{2.5}$ pollution associated with BVOCs led to health damages of 153 million people $\mu \mathrm{g} \mathrm{m}^{-3} \mathrm{O}_{3}$ and 26 million people $\mu \mathrm{g} \mathrm{m}^{-3} \mathrm{PM}_{2.5}$, respectively. Based on a recent metaanalysis of Chinese epidemiology-based exposure-response studies, each unit increase in ozone concentration has a 26\% larger health damage than that of $\mathrm{PM}_{2.5}$ (Shang et al., 2013). We can infer that BVOCs induced ozone pollution played a more important role (88\%) than $\mathrm{PM}_{2.5}$ pollution (12\%) in harming human health. In the urban core with the highest region-based emission intensity and population density, BVOCs emissions had the greatest health damage (Fig. 3C and D); in rural areas, the average health damage was only $1.8 \%$ of the urban core due to the lower population density of these sub-regions. Although the five semi-urban sub-regions had the lowest emission intensities and air quality impacts, the average health damage was three times higher than that in rural areas (Fig. 3C and D). From the human health viewpoint, urban green spaces played much more important roles (62\% of total damage) than natural forests despite its BVOCs emissions only made limited contributions (15\%) to regional emissions (Fig. 4C). These results highlighted that mitigating emissions from green spaces is the key to reducing health impacts associated with BVOCs emissions.

In recent years, the significant high health damages associated with $\mathrm{PM}_{2.5}$ and ozone pollution have been highlighted by many studies (Lelieveld et al., 2015; Madaniyazi et al., 2016) and the potential health damages attributable to BVOCs emissions from urban green spaces discussed (Laothawornkitkul et al., 2009; Simpson and McPherson, 2011). Nevertheless, few measures were actually implemented to reduce BVOCs emissions owing to the lack of accurate forecasts of urban BVOCs emissions and the related environmental and health impacts (Simpson and McPherson, 2011; Ren et al., 2014). Our study developed the relationship between BVOCs emissions and their health damage semi-quantitatively, which was helpful for decision makers to design BVOCs mitigation strategies to achieve the desired environmental and health goals. In this study, only the negative effects of BVOCs emissions on human health were quantified. In fact, many BVOCs species are not only essential for plants to cope with environmental stresses, but also play vital role in promoting physical and mental health of city residents (Ilmberger et al., 2001; Peñuelas and Staudt, 2010). These positive effects should be addressed by future research to achieve a comprehensive evaluation of BVOCs emissions.

\subsection{BVOCs emissions will increase substantially along with rapid urbanization}

The annual BVOCs emissions from urban green spaces in Beijing were 6.5 (3.5-9.3, 95\% confidence interval) $\times 10^{8} \mathrm{~g} \mathrm{C}$ in 1990 , accounting for only $6 \%$ of the regional BVOCs emissions. Since then, along with the fast economic development and urbanization, urban green spaces have expanded rapidly and BVOCs emissions continued to grow. In 2015, the annual BVOCs emission from urban green spaces was $5.0(2.7-7.3) \times 10^{9} \mathrm{~g} \mathrm{C}$; isoprene, monoterpenes, sesquiterpenes and OVOCs contributed 74.0, 15.0, 0.5 and 10.5\%, respectively (Fig. 4A). BVOCs emissions from natural forests also showed a continuous growth trend, increasing from 10.2 $(5.8-13.9) \times 10^{9} \mathrm{~g} \mathrm{C}$ in 1990 to $2.8(1.5-4.0) \times 10^{10} \mathrm{~g} \mathrm{C}$ in 2015 (Fig. 4B).

Following the current trend (baseline scenario), the BVOCs emissions from urban green spaces are projected to rise rapidly and will reach $1.5(0.8-2.2) \times 10^{10} \mathrm{~g} \mathrm{C}$ by 2050 (Fig. 4A), increasing by 203\% compared with emissions in 2015. This increasing rate is larger than those in previous projections on regional (mainly natural vegetation) BVOCs emissions (Wiedinmyer et al., 2006; Heald et al., 2009; Tai et al., 2013). One possible explanation is the fact that most urban trees are relatively young and grow faster than trees in natural forests (Gregg et al., 2003; Ren et al., 2014). 

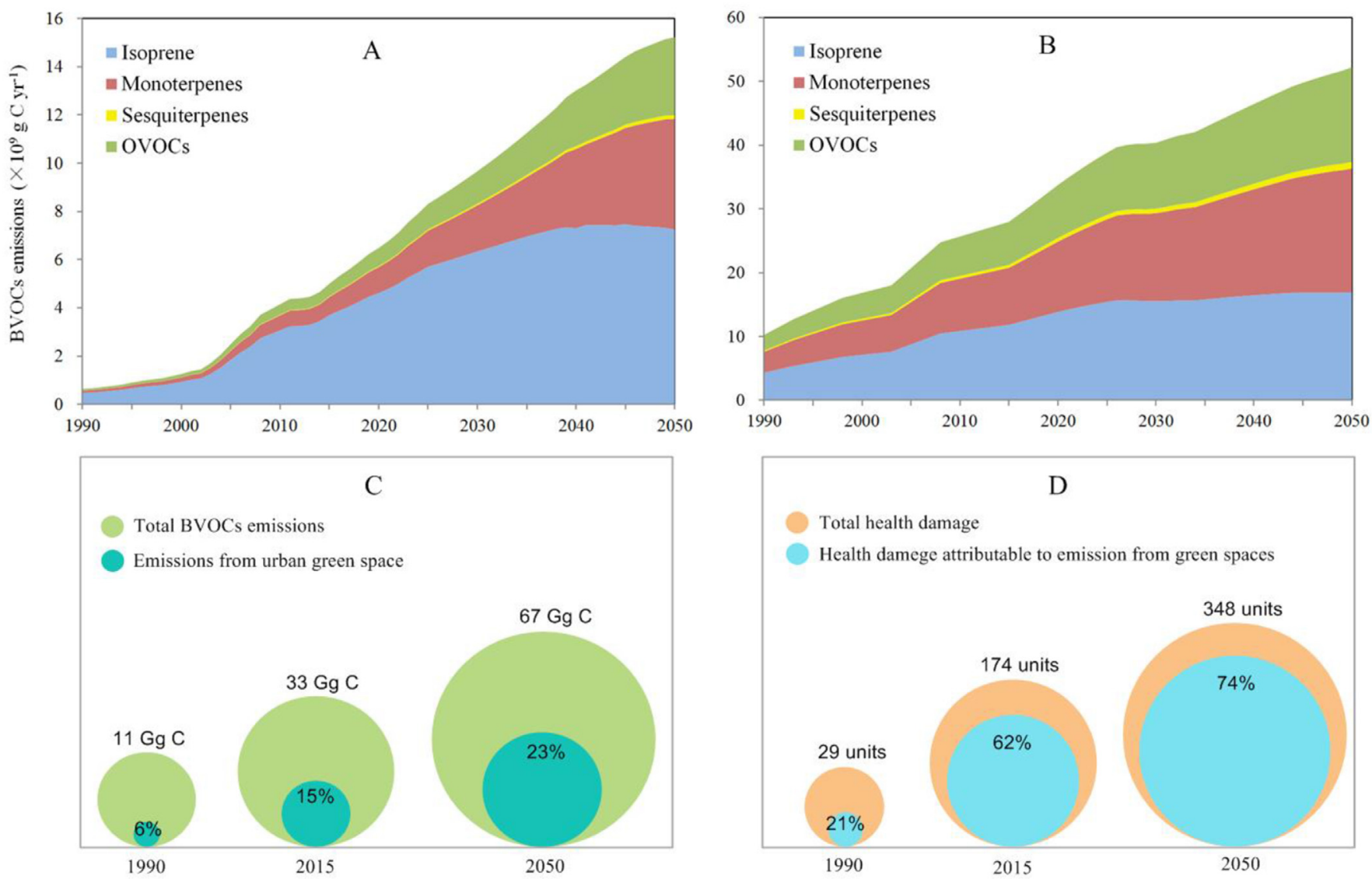

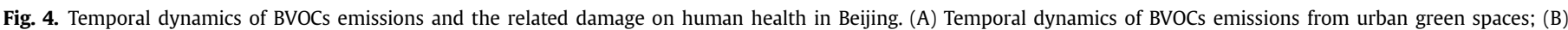

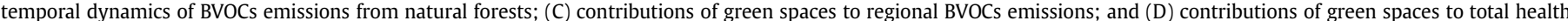
damage ( 1 unit equals to 1 million people $\mu \mathrm{g} \mathrm{m}^{-3} \mathrm{O}_{3}$ ) associated with BVOCs emissions.

Furthermore, we assumed that urban green spaces would continue to expand following the current trend and thus will enhance BVOCs emissions; while in other projections, anthropogenic land use changes tend to lower rural BVOCs emissions by converting forests to croplands, pastures and urban areas (Wiedinmyer et al., 2006; Tai et al., 2013). The BVOCs emissions from the natural forests of Beijing will also greatly increase from 2015 to 2050, though the growth rate $(87 \%)$ is much lower than that of urban green spaces (Fig. 4B). As a result, BVOCs emissions from urban green spaces will continue to make greater contribution to the total emissions of Beijing, from 15\% in 2015 to $23 \%$ by 2050 (Fig. 4C).

In the baseline scenario, as total BVOCs emissions continue to grow, the increments in annual atmospheric ozone and $\mathrm{PM}_{2.5}$ concentrations induced by BVOCs emissions will increase to $9.3 \mu \mathrm{g} \mathrm{m}^{-3}$ and $2.4 \mu \mathrm{g} \mathrm{m}^{-3}$ by 2050 , respectively. The health burden associated with BVOCs emissions increases even faster due to the population growth and will double from 2015 to 2050 (Fig. 4D). During the process, the contributions of urban green spaces to total health damage increase from $62 \%$ in 2015 to $74 \%$ in 2050 (Fig. 4D). BVOCs emissions from urban green spaces will play more important roles in determining future urban air quality and human health conditions.

\subsection{Urban BVOCs emissions can be largely reduced through proactive management}

In the past, BVOCs emissions were often regarded as background emissions that cannot be reduced (Steinbrecher et al., 2009; Ren et al., 2014). This may be true for natural forests, but it is entirely possible to reduce BVOCs emissions from urban green spaces since they are highly controlled by human management (Simpson and McPherson, 2011; Calfapietra et al., 2013).

Tree species optimization is the most feasible way to mitigate BVOCs emissions. Among tree species within urban green spaces of Beijing, Populus tomentosa exhibited the highest BVOCs individual emission potential (967 $\mathrm{g} \mathrm{C}$ tree $\mathrm{er}^{-1}$ ), followed by Sophora japonica (322 g C tree $\mathrm{gr}^{-1}$ ) and Salix babylonica (236 g C tree $\mathrm{yr}^{-1}$ $\left.\mathrm{yr}^{-1}\right)$. Populus canadensis and Albizia julibrissin also had relatively high emission potentials (Fig. 5A). Each BVOCs species has different effects on ozone and $\mathrm{PM}_{2.5}$ formation due to the rates and pathways of their reactions. In general, tree species with high isoprene emissions might enhance ozone formation, while oxidation products of monoterpenes usually have high yields for $\mathrm{PM}_{2.5}$ (Arneth et al., 2010; Aksoyoglu et al., 2011). In Beijing, most of the tree species were strong isoprene emitters, except for strong monoterpenes emitters Pinus tabuliformis and Platycladus orientalis (Fig. 5A). For the purpose of improving air quality, both the speciesspecific emission potentials and chemical speciation of BVOCs emissions should be considered in landscape planning.

When ranking the tree species based on their relative contributions to total emissions, we found that the patterns of urban BVOCs emissions approximately followed power-law distributions ( $R^{2}$ range from 0.88 to $0.96, P<0.001$ ) (Fig. 6). The power $\alpha$ for all BVOCs species were bigger than 1, which means that urban BVOCs emissions are dominated by only a few tree species despite the fact that dozens of tree species were planted (Fig. 5B). The power-law 


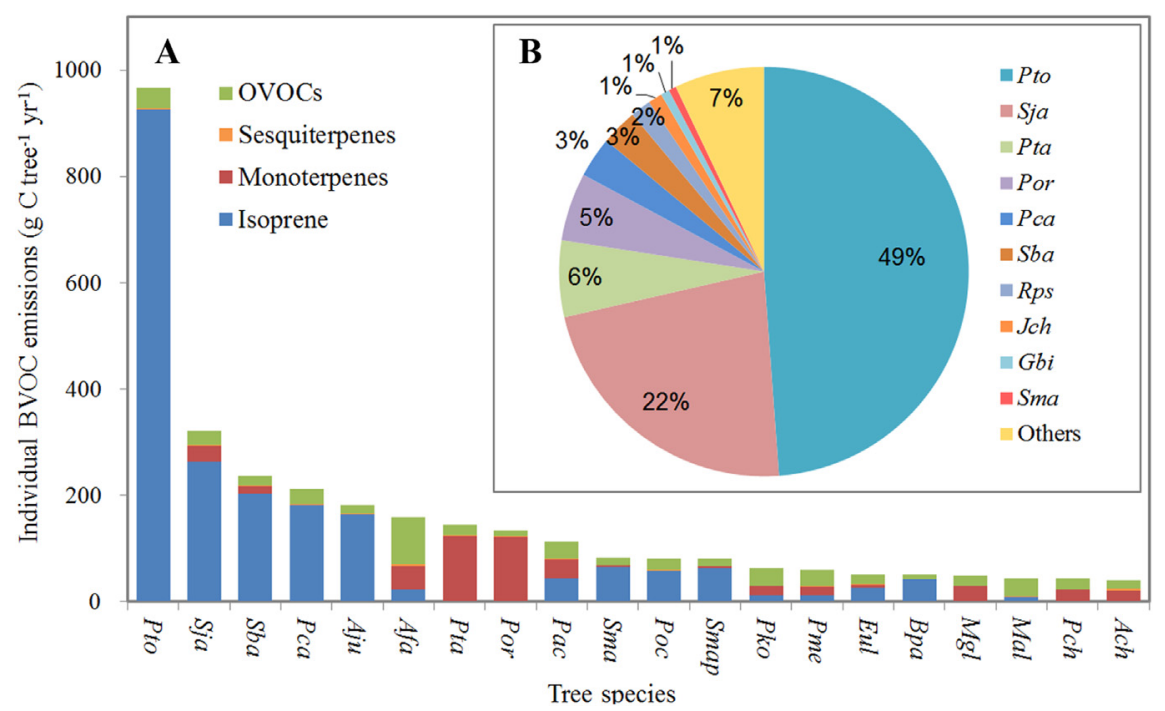

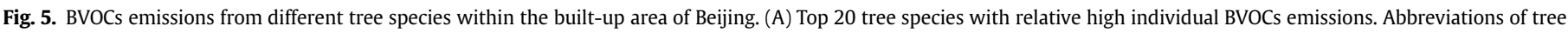
species are summarized in Table S1; (B) contributions of various tree species to BVOCs emissions from green spaces.

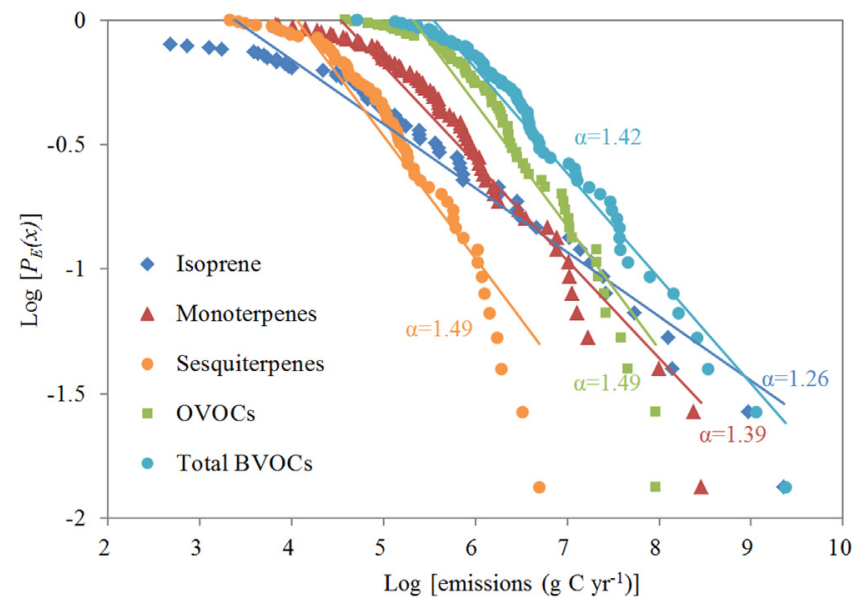

Fig. 6. The power-law distributions of urban BVOCs emissions from different tree species. Exceedance probabilities $P_{E}(x)$ (probability that species' emissions $E$ be $\geq x$ ) were calculated using the rank-frequency approach. Note that in the power-law regime, if the probability distribution $p_{E}(x)$ scales as $x^{-\alpha}$, then $P_{E}(x) \propto x^{-\alpha+1}$.

pattern of urban BVOCs emissions also indicates that the key to mitigating BVOCs emissions is to control those big BVOCs fluxes.

We designed a series of management strategies (S1-S5) to reduce the big BVOCs fluxes. Through directly optimizing the species composition of newly planted trees (S1), moderately increasing tree density (S2), and tree replacement (S3), 20\%, 11\%, 35\% of urban BVOCs reductions can be achieved, respectively (Fig. 7A; Table S14). Mitigating the heat island effect also has the potential to decrease the emissions of all BVOCs species, and a reduction of $14 \%$ of total BVOCs emissions can be achieved if the current urban heat island effect no longer intensifies (S4). The greatest reduction in BVOCs emissions from urban green spaces could be achieved through the integration of all optimization measures (S5). At most, a 61\% reduction in urban BVOCs emissions can be realized by adopting comprehensive management strategies (Fig. 7A). Unlike short-term measures to control AVOCs emissions that have acceptable economic cost (Wang et al., 2015a), the short-term strategies for mitigating BVOCs emissions (e.g., remove all vegetation) often have exorbitant cost thus are too extreme to be adopted. All the long-
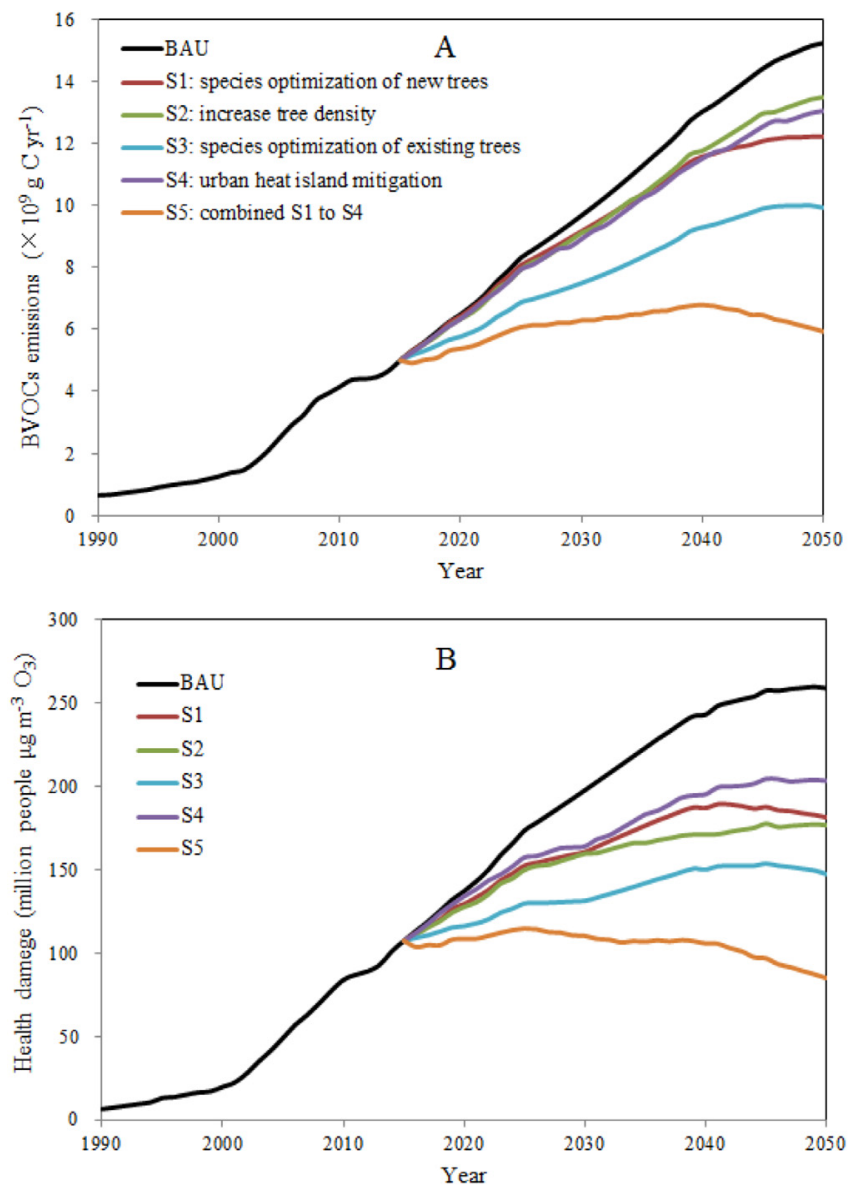

Fig. 7. BVOCs emissions from urban green spaces (A) and the related health damage (B) under different management scenarios.

term management strategies for BVOCs emission mitigation have the time-lag effect (Fig. 7A) and the policy makers need to adopt proactive environmental policies.

BVOCs have drawn increasing attention in recent decades, 
largely due to their human health effects. However, few measures were actually taken to reduce BVOCs emissions owing to the lack of knowledge about what measures should be taken as well as their corresponding effectiveness (Simpson and McPherson, 2011; Ren et al., 2014). Since BVOCs emissions from green spaces happened in urban areas with high population densities, they contributed the most to human health (Fig. 4D). The mitigation of urban emissions is effective at reducing future health damage related to regional BVOCs emissions (Fig. 7B). Under scenarios S1-S4, 16\%-32\% of total health damage will be reduced by 2050 (Table S14). Through the integration of all management strategies (S5), 50\% of the total health damage caused by regional BVOCs emissions can be avoided. Note that all BVOCs reductions and health improvements are realized without the price of productivity decrease and biodiversity loss. This is quite important because urban green spaces also have many important ecosystem services besides BVOCs emissions (Escobedo et al., 2011; Pataki et al., 2011). All decision-making should be based on a trade-off between the ecosystem services and disservices of urban green spaces.

\subsection{Model validation}

BVOCs emissions in Beijing have been estimated using different data sources and algorithms (Wang et al., 2003; Chi and Xie, 2012; Li and Xie, 2014; Ghirardo et al., 2016). The new BVOCs estimates presented in this study were compared to other inventories of Beijing to validate our model performance. For this comparison, BVOCs emissions from other studies were converted to the same scope of our study (i.e. only constitutive emissions from trees were considered). As shown in Fig. 8, the BVOCs variation trends reproduced by our modeling system matched well with simulation results from other studies.

As the BVOCs emissions cannot be evaluated directly, we compared our model predicted monthly average isoprene concentrations in urban areas with the observational data reported in previous studies to further validate our estimates (Fig. 9). Owing to its high reactivity, isoprene may undergo strong photochemical losses and dilution losses from emission sources to receptor sites (Xie et al., 2008; Li et al., 2015b). So to make our results comparable to the observational data, we converted the calculated initial mixing ratios of isoprene to ambient mixing ratios at a receptor site using the isoprene chemistry approach described by Stroud et al. (2001). The method is based on the stoichiometric relationships between methacrolein, methyl vinyl ketone, and isoprene. The details are found in the Appendix. As shown in Fig. 9, though our modeled isoprene mixing ratios have a good linear relationship with the observational data, most of our estimates are slightly lower. One possible explanation is that we only considered isoprene emissions originating from biogenic sources, while vehicle exhaust emission could contribute to isoprene as well (Borbon et al., 2001; Xie et al., 2008). However, Li et al. (2015b) found that isoprene was not correlated with the traces of vehicle exhaust in Beijing, indicating that traffic source was not a significant contributor to isoprene of this region. In general, our BVOCs estimates lie in a reasonable range.

\subsection{Uncertainties}

Based on the Monte Carlo analysis, the uncertainties associated with our estimation of BVOCs induced health damage were between $-79 \%$ and $77 \%$ in 2015 . The major uncertainty came from our estimation of BVOCs emissions $(-47 \%-45 \%)$. Uncertainties related to the basal emission rates, vegetation distributions, model algorithms, empirical coefficients, and leaf biomass equations were all important uncertainty sources of the calculated BVOCs
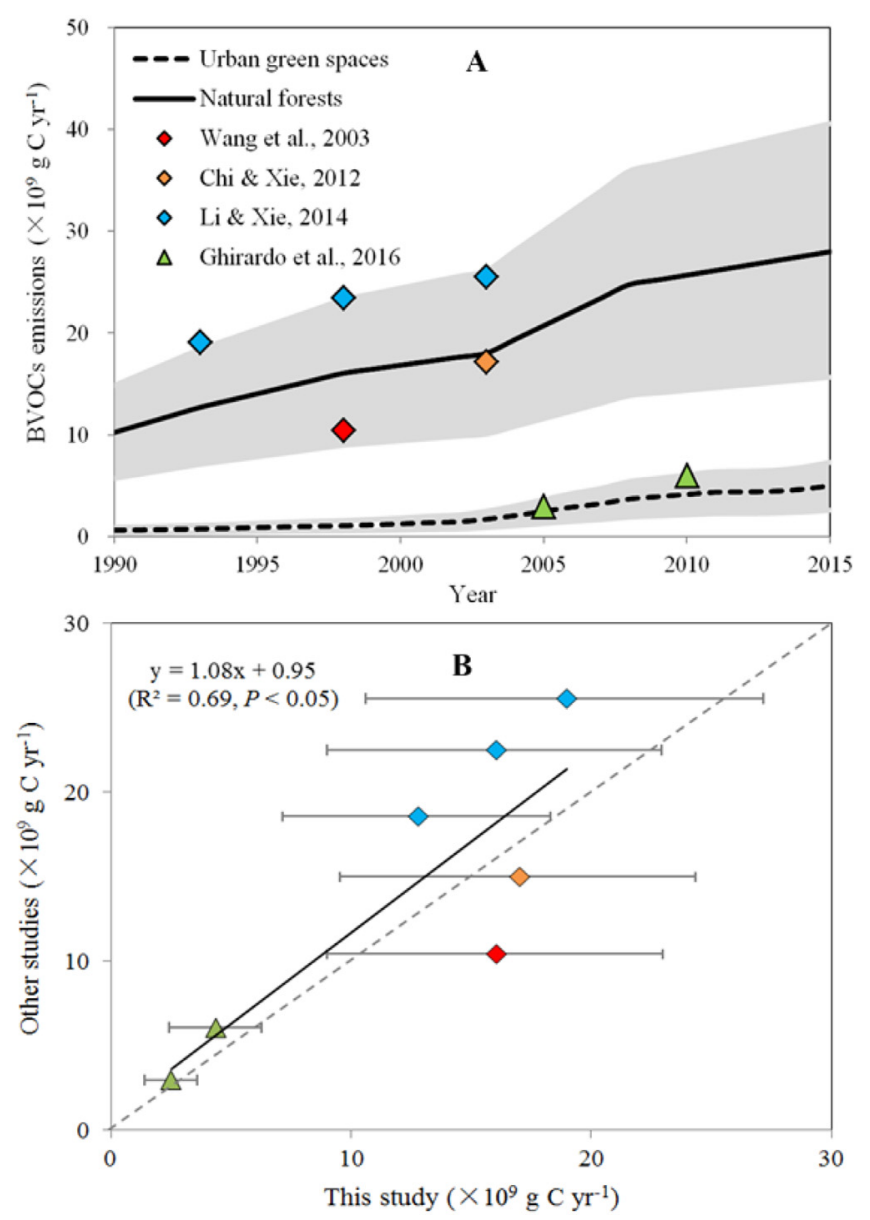

Fig. 8. (A) Temporal dynamics of BVOCs estimates in this study and previous studies: and (B) comparison of our BVOCs estimates with other studies. Triangles and diamonds stand for estimates on BVOCs emissions from urban green spaces and natural forests in Beijing, respectively. Shaded areas denote the $95 \%$ confidence interval on the calculated uncertainties associated with our BVOCs estimates.

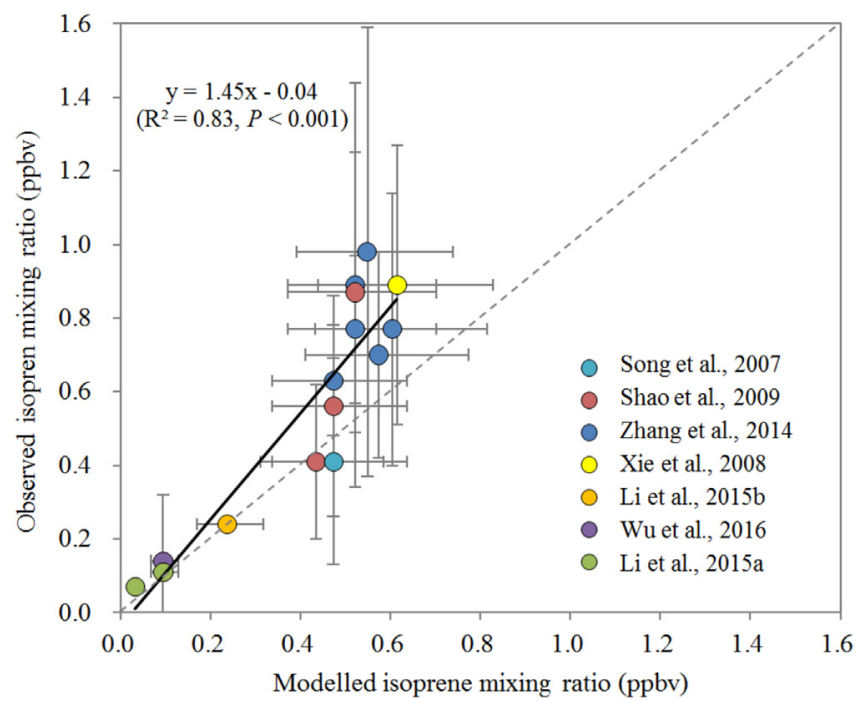

Fig. 9. Comparison of our calculated isoprene mixing ratios and observed data derived from previous studies. Vertical error bars are the standard deviation of observed data, and horizontal error bars represent the 95\% confidential intervals of our estimates ( $\mathrm{Li}$ et al., 2015a; Shao et al., 2009; Song et al., 2007; Wu et al., 2016). 
emissions (Chang et al., 2012).

Another important uncertainty source arises from the estimation of the air quality impacts of BVOCs emissions. This kind of uncertainty is mainly derived from the accuracy of the empirical coefficients of $I R, F A C$ and the atmospheric lifetime of different BVOCs species. Czader et al. (2008) provided an assessment comparing the reactivity estimated from the CMAQ model and the 'reference' incremental reactivity. They found that the reactivity values of most investigated compounds estimated for the HoustonGalveston air conditions are in good agreement with 'reference' values. Even though, it should be noted that the VOC incremental reactivity depends on the relative ratio of VOC to NOx present in the air mixture and no standard reactivity scale that would be suitable to all the conditions. In this study, the average lifetime for reaction with different oxidants was assigned to a specific VOCs species due to the lack of reliable information. In fact, the atmospheric lifetime of VOCs may vary to a large degree depending on the oxidizing environment (Atkinson and Arey, 2003; Oderbolz et al., 2013).

Besides the uncertainty sources considered in the Monte Carlo analysis, there are still some assumptions used in this study that may affect our estimates. Given the growing evidence that urban trees may have high stress-induced BVOCs emissions when suffering environmental stresses (Peñuelas and Staudt, 2010; Mentel et al., 2013), our "stress-free" assumption could result in an underestimation of BVOCs emissions (Ghirardo et al., 2016). We used air temperature instead of leaf temperature to calculate the temperature correction factor as the latter was not available. BVOCs emissions would be underestimated as leaf temperatures are often higher than air temperatures, especially for broad-leaved trees (Leuzinger \& Koerner, 2007). Some uncertainties that are related to the simplified box models used in this study should also be noted. There was a strong assumption underlying the box model that BVOCs emissions only had small spatial scale (local or regional) impacts on air quality and human health within the box. In fact, the surface $\mathrm{O}_{3}$ in urban areas of Beijing was found to be controlled predominantly by in-situ production from local biogenic and anthropogenic VOC emissions (Xu et al., 2011; Zhang et al., 2014). However, urban plume can transport not only $\mathrm{O}_{3}$ but also its precursors to downwind rural areas (Xu et al., 2011). The latter tend to result in more net $\mathrm{O}_{3}$ production when being mixed with local BVOCs. Rural areas usually have weaker NO titration, the level of $\mathrm{O}_{3}$ can be high in late afternoon and during night time (Zhang et al., 2014). So it can be concluded that the simplification that neglecting transport may lead to an underestimation of the health effects of urban BVOCs emissions on downwind rural areas.

\section{Conclusion}

Our study highlights the importance of including BVOCs emissions from urban green spaces when compiling regional BVOCs emission inventories. In 2015, the neglect of BVOCs emissions from urban green spaces led to a $15 \%$ underestimation of regional BVOCs emissions and $62 \%$ underestimation of the health damage caused by BVOCs emissions. As economic development and the urban population continue to grow, the BVOCs emissions within urban areas will be of disproportionate importance for urban air quality and ultimately human health. Fortunately, BVOCs emissions from urban green spaces can be effectively controlled through adopting proactive management strategies.

This study also provides a tool for the analysis and prediction of BVOCs emissions from the urban-rural complex and for the evaluation of related environmental and health outcomes. As many other cities are also experiencing rapid urbanization and urban green space expansion, it is quite possible that these cities may suffer air pollution associated with BVOCs emissions. In the coming decades, a crucial challenge for urban managers and policy makers will be controlling future BVOCs emissions from urban trees and their negative impacts. Given that an accurate assessment of the impacts of BVOCs require a full regional air quality model and should consider all of the processes involved in the reactive carbon cycle in the atmosphere, the lack of a full atmospheric model is a limitation of our work that should be addressed by future research. Although uncertainties exist within the present research, we believe our work is an important step to achieving a better understanding and effective management of urban BVOCs emissions.

\section{Acknowledgements}

This work was financially supported by NSFC (31370354, 31270377 and 31400607). We thank C.H. Peng, X.Y. Ren for their field and lab work, and comments on an earlier version of the manuscript.

\section{Appendix A. Supplementary data}

Supplementary data related to this article can be found at http:// dx.doi.org/10.1016/j.envpol.2017.06.049.

\section{References}

Aksoyoglu, S., Keller, J., Barmpadimos, I., Oderbolz, D., Lanz, V.A., Prevot, A.S.H., Baltensperger, U., 2011. Aerosol modelling in Europe with a focus on Switzerland during summer and winter episodes. Atmos. Chem. Phys. 11 (14), 7355-7373.

Arneth, A., Harrison, S.P., Zaehle, S., Tsigaridis, K., Menon, S., Bartlein, P.J., Feichter, J., Korhola, A., Kulmala, M., O'Donnell, D., Schurgers, G., Sorvari, S., Vesala, T., 2010. Terrestrial biogeochemical feedbacks in the climate system. Nat. Geosci. 3 (8), 525-532.

Atkinson, R., 2000. Atmospheric chemistry of VOCs and NOx. Atmos. Environ. 34 (12-14), 2063-2101.

Atkinson, R., Arey, J., 2003. Gas-phase tropospheric chemistry of biogenic volatile organic compounds: a review. Atmos. Environ. 37, S197-S219.

BGGB (Beijing Gardening and Greening Bureau), 1995-2005. Collection of Beijing Urban Gardening and Afforestation Survey. Beijing Publishing House, Beijing (in Chinese).

Benjamin, M.T., Sudol, M., Bloch, L., Winer, A.M., 1996. Low-emitting urban forests: a taxonomic methodology for assigning isoprene and monoterpene emission rates. Atmos. Environ. 30 (9), 1437-1452.

Benjamin, M.T., Winer, A.M., 1998. Estimating the ozone-forming potential of urban trees and shrubs. Atmos. Environ. 32 (1), 53-68.

BMEPB (Beijing Municipal Environmental Protection Bureau), 2016. Beijing Environmental Statement 2015 (in Chinese). Avaliable: http://www.bjepb.gov.cn/ bjepb/resource/cms/2016/04/2016041514503583104.pdf.

Borbon, A., Fontaine, H., Veillerot, M., Locoge, N., Galloo, J.C., Guillermo, R., 2001. An investigation into the traffic-related fraction of isoprene at an urban location. Atmos. Environ. 35 (22), 3749-3760.

Calfapietra, C., Fares, S., Manes, F., Morani, A., Sgrigna, G., Loreto, F., 2013. Role of Biogenic Volatile Organic Compounds (BVOC) emitted by urban trees on ozone concentration in cities: a review. Environ. Pollut. 183, 71-80.

Calfapietra, C., Penuelas, J., Niinemets, U., 2015. Urban plant physiology: adaptationmitigation strategies under permanent stress. Trends Plant Sci. 20 (2), 72-75.

Carter, W.P.L., 2007. Development of the SAPRC-07 Chemical Mechanism and Updated Ozone Reactivity Scales. California Air Resources Board, Research Division.

Carter, W.P.L., 1994. Development of ozone reactivity scales for volatile organic compounds. J. Air Waste Manage. Assoc. 44 (7), 881-899.

Chang, J., Ren, Y., Shi, Y., Zhu, Y., Ge, Y., Hong, S., Jiao, L., Lin, F., Peng, C., Mochizuki, T., Tani, A., Mu, Y., Fu, C., 2012. An inventory of biogenic volatile organic compounds for a subtropical urban-rural complex. Atmos. Environ. 56, 115-123.

Chen, L., Frauenfeld, O.W., 2016. Impacts of urbanization on future climate in China. Clim. Dynam 47 (1-2), 345-357.

Chi, Y., Xie, S., 2012. Spatiotemporal inventory of biogenic volatile organic compound emissions in China based on vegetation volume and production. Acta Sci. Nat. Univ. Pekin. 48 (3), 475-482.

CNEMC (China National Environmental Monitoring Centre), 2016. Air Quality Report in 74 Chinese Cities in 2015 (in Chinese). Avalilable. http://www.cnemc. cn/publish/106/0536/newList_1.html.

Cumming, G.S., Buerkert, A., Hoffmann, E.M., Schlecht, E., von Cramon-Taubadel, S., Tscharntke, T., 2014. Implications of agricultural transitions and urbanization for ecosystem services. Nature 515 (7525), 50-57.

Czader, B.H., Byun, D.W., Kim, S.-T., Carter, W.P.L., 2008. A study of VOC reactivity in the Houston-Galveston air mixture utilizing an extended version of SAPRC-99 
chemical mechanism. Atmos. Environ. 42 (23), 5733-5742.

Dunn-Johnston, K.A., Kreuzwieser, J., Hirabayashi, S., Plant, L., Rennenberg, H., Schmidt, S., 2016. Isoprene emission factors for subtropical street trees for regional air quality modeling. J. Environ. Qual. 45 (1), 234-243.

Escobedo, F.J., Kroeger, T., Wagner, J.E., 2011. Urban forests and pollution mitigation: analyzing ecosystem services and disservices. Environ. Pollut. 159 (8-9), 2078-2087.

Fang, S.X., Zhou, L.X., Tans, P.P., Ciais, P., Steinbacher, M., Xu, L., Luan, T., 2014. In situ measurement of atmospheric $\mathrm{CO} 2$ at the four WMO/GAW stations in China. Atmos. Chem. Phys. 14 (5), 2541-2554.

Fuller, R.A., Gaston, K.J., 2009. The scaling of green space coverage in European cities. Biol. Lett. 5 (3), 352-355.

Geron, C.D., Guenther, A.B., Pierce, T.E., 1994. An improved model for estimating emissions of volatile organic compounds from forests in the eastern United States. J. Geophys. Research-Atmospheres 99 (D6), 12773-12791.

Ghirardo, A., Xie, J.F., Zheng, X.H., Wang, Y.S., Grote, R., Block, K., Wildt, J., Mentel, T. Kiendler-Scharr, A., Hallquist, M., Butterbach-Bahl, K., Schnitzler, J.P., 2016. Urban stress-induced biogenic VOC emissions and SOA-forming potentials in Beijing. Atmos. Chem. Phys. 16 (5), 2901-2920.

Gregg, J.W., Jones, C.G., Dawson, T.E., 2003. Urbanization effects on tree growth in the vicinity of New York city. Nature 424 (6945), 183-187.

Griffin, R.J., Cocker, D.R., Seinfeld, J.H., Dabdub, D., 1999. Estimate of global atmospheric organic aerosol from oxidation of biogenic hydrocarbons. Geophys. Res. Lett. 26 (17), 2721-2724.

Guenther, A.B., Jiang, X., Heald, C.L., Sakulyanontvittaya, T., Duhl, T., Emmons, L.K., Wang, X., 2012. The Model of Emissions of Gases and Aerosols from Nature version 2.1 (MEGAN2.1): an extended and updated framework for modeling biogenic emissions. Geosci. Model Dev. 5 (6), 1471-1492.

Guenther, A., Baugh, B., Brasseur, G., Greenberg, J., Harley, P., Klinger, L., Serça, D., Vierling, L., 1999. Isoprene emission estimates and uncertainties for the central African EXPRESSO study domain. J. Geophys. Res. 104 (D23), 30625-30639.

Guenther, A., Hewitt, C.N., Erickson, D., Fall, R., Geron, C., Graedel, T., Harley, P., Klinger, L., Lerdau, M., McKay, W.A., Pierce, T., Scholes, B., Steinbrecher, R. Tallamraju, R., Taylor, J., Zimmerman, P., 1995. A global model of natural volatile organic compound emissions. J. Geophys. Res. 100 (D5), 8873-8892.

Guo, P., Guo, K., Ren, Y., Shi, Y., Chang, J., Tani, A., Ge, Y., 2013. Biogenic volatile organic compound emissions in relation to plant carbon fixation in a subtropical urban-rural complex. Landsc. Urban Plan. 119, 74-84.

Harrison, S.P., Morfopoulos, C., Dani, K.G.S., Prentice, I.C., Arneth, A., Atwell, B.J., Barkley, M.P., Leishman, M.R., Loreto, F., Medlyn, B.E., Niinemets, U., Possell, M., Penuelas, J., Wright, I.J., 2013. Volatile isoprenoid emissions from plastid to planet. New Phytol. 197 (1), 49-57.

Heal, M.R., Heaviside, C., Doherty, R.M., Vieno, M., Stevenson, D.S., Vardoulakis, S., 2013. Health burdens of surface ozone in the UK for a range of future scenarios. Environ. Int. 61, 36-44.

Heald, C.L., Wilkinson, M.J., Monson, R.K., Alo, C.A., Wang, G., Guenther, A., 2009. Response of isoprene emission to ambient $\mathrm{CO}_{2}$ changes and implications for global budgets. Glob. Change Biol. 15 (5), 1127-1140.

Ilmberger, J., Heuberger, E., Mahrhofer, C., Dessovic, H., Kowarik, D., Buchbauer, G., 2001. The influence of essential oils on human attention. I Alertness. Chem. Senses 26 (3), 239-245.

Karl, M., Tsigaridis, K., Vignati, E., Dentener, F., 2009. Formation of secondary organic aerosol from isoprene oxidation over Europe. Atmos. Chem. Phys. 9 (18), 7003-7030.

Kaye, J.P., Groffman, P.M., Grimm, N.B., Baker, L.A., Pouyat, R.V., 2006. A distinct urban biogeochemistry? Trends Ecol. Evol. 21 (4), 192-199.

Kiendler-Scharr, A., Andres, S., Bachner, M., Behnke, K., Broch, S., Hofzumahaus, A., Holland, F., Kleist, E., Mentel, T.F., Rubach, F., Springer, M., Steitz, B., Tillmann, R. Wahner, A., Schnitzler, J.P., Wildt, J., 2012. Isoprene in poplar emissions: effects on new particle formation and OH concentrations. Atmos. Chem. Phys. 12 (2), 1021-1030.

Klinger, L.F., Li, Q.J., Guenther, A.B., Greenberg, J.P., Baker, B., Bai, J.H., 2002. Assessment of volatile organic compound emissions from ecosystems of China. J. Geophys. Research-Atmospheres 107 (D21).

Laothawornkitkul, J., Taylor, J.E., Paul, N.D., Hewitt, C.N., 2009. Biogenic volatile organic compounds in the Earth system. New Phytol. 183 (1), 27-51.

Lelieveld, J., Evans, J.S., Fnais, M., Giannadaki, D., Pozzer, A., 2015. The contribution of outdoor air pollution sources to premature mortality on a global scale. Nature 525 (7569), 367-371.

Leuzinger, S., Koerner, C., 2007. Tree species diversity affects canopy leaf temperatures in a mature temperate forest. Agric. For. Meteorology 146 (1-2), 29-37.

Li, J.W., Jiang, Y.S., Zhang, Z.X., et al., 2011. Distribution and Conservation Management of Forest Plant Diversity in Beijing. Science Press, Beijing (in Chinese).

Li, J., Wu, R., Li, Y., Hao, Y., Xie, S., Zeng, L., 2016a. Effects of rigorous emission controls on reducing ambient volatile organic compounds in Beijing, China. Sci. Total Environ. 557, 531-541.

Li, J., Xie, S.D., Zeng, L.M., Li, L.Y., Li, Y.Q., Wu, R.R., 2015a. Characterization of ambient volatile organic compounds and their sources in Beijing, before, during, and after Asia-pacific economic cooperation China 2014. Atmos. Chem. Phys. 15 (14), 7945-7959.

Li, L.Y., Xie, S.D., 2014. Historical variations of biogenic volatile organic compound emission inventories in China, 1981-2003. Atmos. Environ. 95, 185-196.

Li, L., An, J.Y., Shi, Y.Y., Zhou, M., Yan, R.S., Huang, C., Wang, H.L., Lou, S.R., Wang, Q., Lu, Q., Wu, J., 2016b. Source apportionment of surface ozone in the Yangtze River Delta, China in the summer of 2013. Atmos. Environ. 144, 194-207.
Li, L., Xie, S., Zeng, L., Wu, R., Li, J., 2015b. Characteristics of volatile organic compounds and their role in ground-level ozone formation in the Beijing-TianjinHebei region, China. Atmos. Environ. 113, 247-254.

Luo, Y.J., Wang, X.K., Lu, F., et al., 2013. Biomass and its Allocation of Forest Ecosystems in China. China Forestry Publishing House, Beijing (in Chinese).

Madaniyazi, L., Nagashima, T., Guo, Y.M., Pan, X.C., Tong, S.L., 2016. Projecting ozonerelated mortality in East China. Environ. Int. 92-93, 165-172.

Meier, F., Scherer, D., 2012. Spatial and temporal variability of urban tree canopy temperature during summer 2010 in Berlin, Germany. Theor. Appl. Climatol. 110 (3), 373-384.

Mentel, T.F., Kleist, E., Andres, S., Dal Maso, M., Hohaus, T., Kiendler-Scharr, A., Rudich, Y., Springer, M., Tillmann, R., Uerlings, R., Wahner, A., Wildt, J., 2013. Secondary aerosol formation from stress-induced biogenic emissions and possible climate feedbacks. Atmos. Chem. Phys. 13 (17), 8755-8770.

Mochizuki, T., Miyazaki, Y., Ono, K., Wada, R., Takahashi, Y., Saigusa, N., Kawamura, K., Tani, A., 2015. Emissions of biogenic volatile organic compounds and subsequent formation of secondary organic aerosols in a Larix kaempferi forest. Atmos. Chem. Phys. 15 (20), 12029-12041.

NBSC (National Bureau of Statistics of China), 1991-2015. China City Statistical Yearbook. China Statistics Press, Beijing (in Chinese).

NBSC (National Bureau of Statistics of China), 2010-2016. China Statistical Yearbook. China Statistics Press, Beijing (in Chinese).

Niinemets, U., Peñuelas, J., 2008. Gardening and urban landscaping: significant players in global change. Trends Plant Sci. 13 (2), 60-65.

Nishimura, H., Shimadera, H., Kondo, A., Akiyama, K., Inoue, Y., 2015. Numerical analysis on biogenic emission sources contributing to urban ozone concentration in Osaka, Japan. Asian J. Atmos. Environ. 9 (4), 259-271.

Oderbolz, D.C., Aksoyoglu, S., Keller, J., Barmpadimos, I., Steinbrecher, R., Skjoth, C.A. Plass-Duelmer, C., Prevot, A.S.H., 2013. A comprehensive emission inventory of biogenic volatile organic compounds in Europe: improved seasonality and landcover. Atmos. Chem. Phys. 13 (4), 1689-1712.

Papiez, M.R., Potosnak, M.J., Goliff, W.S., Guenther, A.B., Matsunaga, S.N., Stockwell, W.R., 2009. The impacts of reactive terpene emissions from plants on air quality in Las Vegas, Nevada. Atmos. Environ. 43 (27), 4109-4123.

Pataki, D.E., Carreiro, M.M., Cherrier, J., Grulke, N.E., Jennings, V., Pincetl, S., Pouyat, R.V., Whitlow, T.H., Zipperer, W.C., 2011. Coupling biogeochemical cycles in urban environments: ecosystem services, green solutions, and misconceptions. Front. Ecol. Environ. 9 (1), 27-36.

Peñuelas, J., Staudt, M., 2010. BVOCs and global change. Trends Plant Sci. 15 (3), 133-144.

Ramalho, C.E., Hobbs, R.J., 2012. Time for a change: dynamic urban ecology. Trends Ecol. Evol. 27 (3), 179-188.

Ren, Y., Ge, Y., Gu, B.J., Min, Y., Tani, A., Chang, J., 2014. Role of management strategies and environmental factors in determining the emissions of biogenic volatile organic compounds from urban greenspaces. Environ. Sci. Technol. 48 (11), 6237-6246.

Seto, K.C., Gueneralp, B., Hutyra, L.R., 2012. Global forecasts of urban expansion to 2030 and direct impacts on biodiversity and carbon pools. Proc. Natl. Acad. Sci. U. S. A. 109 (40), 16083-16088.

Shang, Y., Sun, Z.W., Cao, J.J., Wang, X.M., Zhong, L.J., Bi, X.H., Li, H., Liu, W.X., Zhu, T. Huang, W., 2013. Systematic review of Chinese studies of short-term exposure to air pollution and daily mortality. Environ. Int. 54, 100-111.

Shao, M., Lu, S., Liu, Y., Xie, X., Chang, C., Huang, S., Chen, Z., 2009. Volatile organic compounds measured in summer in Beijing and their role in ground-level ozone formation. J. Geophys. Research-Atmospheres 114.

Simpson, J.R., McPherson, E.G., 2011. The tree BVOC index. Environ. Pollut. 159 (8-9), 2088-2093.

Song, Y., Shao, M., Liu, Y., Lu, S., Kuster, W., Goldan, P., Xie, S., 2007. Source apportionment of ambient volatile organic compounds in Beijing. Environ. Sci. Technol. 41 (12), 4348-4353.

State Forest Administration of China (SFAC), 1982-2010. National Forest Resources Statistics. China Forestry Publishing House, Beijing (in Chinese)

Staudt, M., Bertin, N., Frenzel, B., Seufert, G., 2000. Seasonal variation in amount and composition of monoterpenes emitted by young Pinus pinea trees - implications for emission modeling. J. Atmos. Chem. 35 (1), 77-99.

Steinbrecher, R., Smiatek, G., Koeble, R., Seufert, G., Theloke, J., Hauff, K., Ciccioli, P., Vautard, R., Curci, G., 2009. Intra- and inter-annual variability of VOC emissions from natural and semi-natural vegetation in Europe and neighbouring countries. Atmos. Environ. 43 (7), 1380-1391.

Stroud, C.A., Roberts, J.M., Goldan, P.D., Kuster, W.C., Murphy, P.C., Williams, E.J., Hereid, D., Parrish, D., Sueper, D., Trainer, M., Fehsenfeld, F.C., Apel, E.C., Riemer, D., Wert, B., Henry, B., Fried, A., Martinez-Harder, M., Harder, H., Brune, W.H., Li, G., Xie, H., Young, V.L., 2001. Isoprene and its oxidation products, methacrolein and methylvinyl ketone, at an urban forested site during the 1999 southern oxidants study. J. Geophys. Research-Atmospheres 106 (D8) $8035-8046$.

Sun, J., Wu, F., Hu, B., Tang, G., Zhang, J., Wang, Y., 2016. VOC characteristics, emissions and contributions to SOA formation during hazy episodes. Atmos. Environ. 141, 560-570.

Tai, A.P.K., Mickley, L.J., Heald, C.L., Wu, S., 2013. Effect of $\mathrm{CO}_{2}$ inhibition on biogenic isoprene emission: implications for air quality under 2000 to 2050 changes in climate, vegetation, and land use. Geophys. Res. Lett. 40 (13), 3479-3483.

Tani, A., Kawawata, Y., 2008. Isoprene emission from the major native Quercus spp. in Japan. Atmos. Environ. 42 (19), 4540-4550.

Unger, N., 2014. Human land-use-driven reduction of forest volatiles cools global 
climate. Nat. Clim. Change 4 (10), 907-910

Wang, M., Shao, M., Chen, W., Lu, S., Liu, Y., Yuan, B., Zhang, Q., Chang, C.C., Wang, B. Zeng, L., Hu, M., Yang, Y., Li, Y., 2015a. Trends of non-methane hydrocarbons (NMHC) emissions in Beijing during 2002-2013. Atmos. Chem. Phys. 15 (3) 1489-1502.

Wang, Z.H., Bai, Y.H., Zhang, S.Y., 2003. A biogenic volatile organic compounds emission inventory for Beijing. Atmos. Environ. 37 (27), 3771-3782.

Wang, Z., Li, Y., Chen, T., Zhang, D., Sun, F., Wei, Q., Dong, X., Sun, R., Huan, N., Pan, L. 2015b. Ground-level ozone in urban Beijing over a 1-year period: temporal variations and relationship to atmospheric oxidation. Atmos. Res. 164, 110-117.

Wiedinmyer, C., Tie, X., Guenther, A., Neilson, R., Granier, C., 2006. Future changes in biogenic isoprene emissions: how might they affect regional and global atmospheric chemistry? Earth Interact. 10.

Wu, R., Li, J., Hao, Y., Li, Y., Zeng, L., Xie, S., 2016. Evolution process and sources of ambient volatile organic compounds during a severe haze event in Beijing, China. Sci. Total Environ. 560, 62-72.
Xie, X., Shao, M., Liu, Y., Lu, S., Chang, C.C., Chen, Z.M., 2008. Estimate of initial isoprene contribution to ozone formation potential in Beijing, China. Atmos. Environ. 42 (24), 6000-6010.

Xu, J., Ma, J.Z., Zhang, X.L., Xu, X.B., Xu, X.F., Lin, W.L., Wang, Y., Meng, W., Ma, Z.Q., 2011. Measurements of ozone and its precursors in Beijing during summertime: impact of urban plumes on ozone pollution in downwind rural areas. Atmos. Chem. Phys. 11 (23), 12241-12252.

Zhang, Q., Yuan, B., Shao, M., Wang, X., Lu, S., Lu, K., Wang, M., Chen, L., Chang, C.C., Liu, S.C. 2014. Variations of ground-level O-3 and its precursors in Beijing in summertime between 2005 and 2011. Atmos. Chem. Phys. 14 (12), 6089-6101. Zhao, N., Liu, S.H., Yu, H.Y., 2011. Urbanization effects on local climate in Beijing in recent 48 years. Chin. J. Atmos. Sci. 35 (2), 373-385 (in Chinese).

Zheng, J.Y., Shao, M., Che, W.W., Zhang, L.J., Zhong, L.J., Zhang, Y.H., Streets, D., 2009. Speciated VOC emission inventory and spatial patterns of ozone formation potential in the pearl river delta, China. Environ. Sci. Technol. 43 (22), $8580-8586$ 